\title{
Utilizing MAR for Remedial Teaching of Compound-Cube-Surface Area at Elementary School in Taiwan
}

Koun Tem Sun, National University of Tainan, Tainan, Taiwan

Meng Hsun Chen, National University of Tainan, Tainan, Taiwan

\begin{abstract}
In this paper, the development of the MAR (mobile augmented reality) remedial teaching program is described. It allowed students to manipulate augmented objects through AURASMA app via internet and find leads to solve geometry problems regarding compound-cube-surface area. In order to foster students' spatial abilities, the program provided specific functions included partition, complementation, recombination, and multi-perspective to promote their "mental image" as well as "visualization." The proposed program was evaluated with the quasi-experimental pre-test/post-test control group design to probe into students' learning performance. Moreover, students' error types of problem-solving were analyzed using their solving track recorded in the sheets. The results showed that the MAR remedial teaching program truly benefit students on solving geometry problems regarding compoundcube-surface area, and there are still some questions needed to investigate in the future, such as how students were affected by visual-obscuration to inexactly carry out their counts.
\end{abstract}

\section{KEYWORDS}

AR, Augmented Reality, Compound Cube Surface Area, E-Learning, Geometry, Geometry Problem Solving, Mathematic, M-Learning, U-Learning, Virtual Objects

\section{INTRODUCTION}

After the publication of Hiebert's edited book (1986), Mathematical knowledge had been recognized mostly in the form of conceptual and procedural knowledge (Putnam, 1986). Conceptual knowledge is connected web of knowledge and rich in relationships; procedural knowledge is composed of both the knowledge of mathematical symbols and the knowledge of algorithms or procedures that "step-by-step instructions that prescribe how to complete tasks" (Putnam, 1986). A bulk of research and theory in cognitive science supports the notions that deep understanding depends on how well a learner represents and connects bits of knowledge (Kilparick, Swafford \& Findell, 2001). Success in mathematics, furthermore, relies mostly on how learners internalize the meaning related to a procedure they are learning or a concept that is being taught and connections made between them (Gulcin \& Meral, 2015).

Several research studies have pointed out that most of the teachers prefer to introduce concepts of measurement via formulae instead of using students' conceptions of space and 
measurement (Smith, 2007; Thompson, Philipp, Thompson \& Boyd, 1994). According to Gulcin \& Meral's study (2015), the findings of the current study clearly Indicated that the students could not be able to make sense of the foundational principle behind volume measurement which requires more complex reasoning about the structure of space than measuring two- or onedimensional regions. In addition, lack of spatial visualization and of meaningful enumeration of arrays of cubes as well as poor understanding in length and area measurement might be the reasons behind the several errors of the students in volume measurement (Gulcin \& Meral, 2015). It is particularly significant in learning compound cube surface area. Accordingly, it is essential to build a bridge which connected concepts of measurement and procedure of measurement. Besides it, this bridge play multiple roles such as scaffolding for spatial visualization and procedure meaning of measurement, and assistance of Inquiry Learning. Further, traditional schoolbooks do not represent the source of actual knowledge whereas creation of electronic manuals often becomes a "wrapping " of old content in a new form (Sergey, Fedor, Pavel, \& Pavel, 2015). Manipulating physical cubes or blocks is considered as the best way for students on learning spatial concepts due to children's development stages, but sometimes it appeared to form influence in comprehending relationship between lines and surfaces because of the real-object physical property. For example, the activity regarding partitioning the compound-body to regular ones may be a loading task for students and it would result in miscounting on following work regarding measuring the length of relative lines. Augmented reality (abbreviated AR) is between real and virtual environment closer to real. It could not only provide students the visualization and interactivity of real-objects by virtual objects, but also the convenient access in anytime and anywhere. It could assist students in reducing the above-mentioned loading or miscounting. Besides, ARis a technology that augments or superimposes a real time image of the real world with either two (2D) or three-dimension (3D) Computer Generated (CG) object, allowing users to interact with them (Azuma et all., 2001). Moreover, AR is used more widely now not only because new AR applications are supported by computers and mobile devices (smartphone, tablet PC, etc.) (Wu, Lee, Chang, \& Liang, 2013), but also mobile devices with improved hardware properties are available at lower prices as well as so the use of AR technology use not as difficult as it once was (Gervautz \& Schmalstieg, 2012; Squire \& Klopfer, 2007).

Consequently, mobile-augmented reality will be the appropriate technology as the key of bridge which was indicated above to solve the task mentioned above. Researchers utilized free mobile-augmented reality app to create the presentation of compound cube volume by virtual objects, which give children closer to real objects. On top of that, the presentation could be rotated, separated, and recombined by repeatedly touching tablet which could foster observation of relations between lengths and areas to complete the spatial concept of compound-cube-surface area. Hence, the characterization played essential roles in scaffolding students' spatial visualization and procedure meaning of measurement, and assistance of Inquiry Learning. Thereby, we designed a remedial instruction in which students was learned and realized the conceptual and procedural knowledge of compound cube surface area through the operation of paper hollow cubes, interaction of augmented compound bodies, observation of interacted with augmented compound bodies, recording of the side lengths in need, counting of the each compound-cube-surface area, and presentation of the compound-cube-surface areas counting by each group.

The purpose of this study was to design a remedial teaching program regarding compound-cubesurface areas measurement via mobile-augmented reality (MAR) technology to improve students' learning performance and to analyze the influence of theirs' learning change. 


\section{THEORETICAL BACKGROUND}

\section{Spatial Ability in 3-Dimensional Geometry - Mental Image and Visualization}

Plane representations are the most frequent type of representation mode used to represent 3D geometrical objects in school mathematics and sometimes are considered in the teaching process as if they were real objects (Berthelot \& Salin, 1998). However, Parzysz (1998) and Duval (1998) who pointed out that the representation of a $3 \mathrm{D}$ object by means of a $2 \mathrm{D}$ figure demands considerable conventionalizing which is not trivial and not taught in school. In spite of the 3-dimensional aspect of the objects presented on the screen, they, like pictures, are plane representations of spatial objects, so some of the well-known difficulties students have when interpreting traditional plane representations of solids appear in computer environment too (Gutiérrez, 1996). As we informal observed from educational field, we found the majority of students have difficulties in solving the problems involving $3 \mathrm{D}$ cubes and measuring the compound cube volume and their surface area in particular. We suspect that students did not have well-done spatial abilities resulting in triggering these difficulties. Brown and Wheatly (1997) indicated that the representation of 3D objects by 2D nets is directly related to students' ability to combine and analyze visual images, for instance, to analyze a visual image to its component parts and then to recombine these parts to new images. In consequence, to solve the problems regarding 3D cubes or measurement of the compound cube volume and their surface area were difficulty tasks for students, because of the materials in textbook which composed of 3D object by means of a 2D figure as well as it need students have efficiency abilities to combine and analyze visual image.

Battista (2003) suggested that students should develop two necessary skills to calculate conceptually the volume and surface area of solid: (a) the conceptualization of the numerical operations and the link of the formulas with the structure of the solid; (b) the understanding and visualization of the internal structure of the solid. Kosslyn (1980) brought up two terminologies as "mental image" and "visualization" to depict students' development with respect to spatial abilities. A "mental image" is a mental representation of a mathematical concept or property containing information based on pictorial, graphical or diagrammatic elements. "Visualization" is the kind of reasoning based on the use of mental images. In opposition to the approach of cognitive psychologist, mathematics educators consider that mental images and external representations have to interact to achieve a better understanding and to solve problems. Visualization is the context where this interaction takes place (Zimmermann \& Cunningham, 1991). As to visualization, Bishop (1980;1983) recognizes two abilities in visualization: (a) the "visual processing" of information (abbreviated VP), including the manipulation and transformation of visual representations and visual imagery and the visualization of abstract relationships into visual terms; (b) the "interpretation of the figural information" (abbreviated IFI), involving understanding the visual representations and spatial vocabulary used in geometric work, graphs, charts, and diagrams of all types.

Kosslyn (1980) identifies four processes applicable to visualization and mental images: (a) Generating a mental image from some given information; (b) Inspecting a mental image to observe its position or the presence of parts of elements; (c) Transforming a mental image by rotating, translating, scaling, or decomposing it; (d) Using a mental image to answer questions.

McGee (1979) describes ten different spatial abilities, distributed into two classes:

- Abilities of spatial visualization: (a) Ability to imagine the rotation of a depicted object, the (un)folding of a solid, and the relative changes of position of objects in space; (b) Ability to visualize a configuration in which there is movement among its parts; (c) Ability to comprehend imaginary movements in three dimensions, and to manipulate objects in the imagination; (d) Ability to manipulate or transform the image of a spatial pattern into other arrangement;

- Abilities of spatial orientation: (a) Ability to determine relationships between different spatial objects; (b) Ability to recognize the identity of an object when it is seen from different angles, 
or when the object is move; (c) Ability to consider spatial relations where the body orientation of the observer is essential; (d) Ability to perceive spatial patterns and to compare them with each other; (e) Ability to remain unconfused by the varying orientations in which a spatial object may be presented; (f) Ability to perceive spatial patterns or to maintain orientation with respect to objects in space.

In summary, spatial abilities are important for comprehending abstract spatial re-presentations in mathematical problem solving (Waller,2005). Furthermore, mental image and visualization are being considered the key factors both for fostering students' spatial abilities and instructional design. In addition, VP and IFI both are essential processes for visualization. Given above, we will refer to those aspects which were mentioned above with regard to spatial abilities so as to design appropriate remedial teaching of compound-cube-surface areas for improving students' performance in such unit field.

\section{Mobile Augmented Reality}

A bulk of studies have found that mobile devices play a major role in education now-days and see the impact and advantages of these device in regard to the potential for pedagogical perspective (Chen, Kao, \& Sheu, 2003; Denk, Weber, \& Belfin, 2007; FitzGerald, Adams, Ferguson, Gaved, Mor \& Thomas, 2012; Hwang, Yang, Tsai, \& Yang, 2009; Uzunboylu, Cavus, \& Ercag, 2009; Zurita \& Nussbaum, 2004). On the other hand, the widespread use of AR on mobile device such as smartphone and tablets has become a growing phenomenon due to the rising popularity of mobile devices globally (Danakorn, Mohamad, Noor, \& Mohd, 2013). Thus, more and more instructors were engaged in integrating MAR technology with relevant subject unit learning. Arvanitis (et al.,2007) utilized MAR technology based system which was called "CONNECT" via a head mounted display (HMD) and related computer- mediated learning platform to visualize and interact physically and intellectually with learning environment that deal with instructional materials, through "hands on" experimentation and "minds on" reflection. Schmalstieg and Wagner (2007) integrated handheld Augmented Reality and two mobile games that were developed by researchers to evaluate students' motivation and satisfaction. Researchers named two games are "medien.welten" and "Expedition Schatzsuche". Tarng and Ou (2012) used AR and mobile technologies as an assistant tool for learning butterfly ecology in which students can breed their own virtual caterpillars on host plants using the programs on their smart phones, and become familiar with butterfly's life cycle by observing their growth. Santoso, Yan and Gook (2012) developed the application to enhance student spatial cognitive ability that was composed of a Digital Edutainment Content based on Tangram toy and ipad version where the built-in camera will be activated automatically once the user choose an AR session. Martín, Díaz, Cáceres, Gago, \& Gibert, (2012) utilized mobile device based on geolocalisation and AR technology to build an educational application called "EnredaMadrid" to teach the history of the city in the 17 th century to students in the activity through previous online training and a later physical technological gymkhana. Sommerauer \& Müller (2014) conducted a field experiment in a mathematics exhibition based on AR. The empirical results revealed museum visitors performed significantly better on knowledge acquisition and retention tests related to augmented exhibits than to non-augmented exhibits.

In sum, we can conclude that MAR is benefit to motivate students' leaning behaviors and to improve student learning performance. Particularly, the main characteristics of MAR are visualization and interaction and that motivate students to learn more clearly and provide them optimum exploring route. In this paper, we will utilize these characteristics to develop several augmented compoundcube -surface area prototypes to assist students on learning and to investigate the influence of theirs' learning performance and processes. 


\section{METHODS}

\section{Research Methods}

A quasi-experimental pre-test/post-test control group design (Campbell \& Stanley, 1996) was used in this study. While the experimental group used augmented compound cube surface area materials, the control group used a traditional textbook.

\section{Participants}

The participants were $6^{\text {th }}$ grade students in elementary school during 2016-2017 academic year. There are two classes of $6^{\text {th }}$ grade students in the department (A and B). Randomly, Class A was designed as the experimental group, and Class B was assigned as the control group. In total, 60 students age 11-12 participated in the study (see Table 1).

\section{Experimental Procedure}

This study was conducted within the context of the course Mathematic at elementary school. The course is taught for forty minutes for each class, 5-class per-week. The same instructor is responsible for both of the classes. He offers guidance and assistance when needed.

The augmented compound-cube-surface area materials was initiated before mid-term exam week of the Spring term in the 2017 academic year and was conducted for six weeks. Before experimenting, all of the participants take the pre-test regarding the subject of compound-cube-surface area. The statistic of the pre-test reveals (Table 2), the mean pretest score of the experimental group is lower than the control one, but that is not reach the significant difference on statistic $(\mathrm{F}=.060, \mathrm{P}=0.808>.01)$. In the other words, the two groups both are in the same initial abilities regarding compound-cube-surface area. Besides, the researchers found that the types of mistakes regarding pretest include five major types, such as confusing between volume and surface area, counting missing, repeatedly counting, measuring the surface area by development drawing is incomplete, and others. So as to improve these mistakes, the researchers developed the interactive MAR objects which scaffold students' operating and observation on the transformation of objects, such as partition, complementation, and recombination. Students can easily engage themselves in activities anywhere and anytime if Internet access is available. All participants performed 3 assignments (see Table 3) within 5 weeks. During the five-week period, the control group students conducted their experiments using a traditional textbook only in the Mathematic class. The experimental group students conducted their experiment

Table 1. Subjects statistics

\begin{tabular}{|l|l|l|}
\hline \multicolumn{1}{|c|}{ Gender } & \multicolumn{1}{|c|}{ Experimental Group } & \multicolumn{1}{c|}{ Control Group } \\
\hline Female & 15 & 15 \\
\hline Male & 14 & 15 \\
\hline Total & 30 & 30 \\
\hline
\end{tabular}

Table 2. The statistic of the pre-test

\begin{tabular}{|c|c|c|c|}
\hline & \multirow{2}{*}{$\mathbf{N}$} & \multicolumn{2}{|c|}{ Pretest Scores } \\
\hline & & Mean & Standard Deviation \\
\hline Augmented instrument & 30 & 32.67 & 22.427 \\
\hline Non-Augmented instrument & 30 & 40.17 & 19.230 \\
\hline
\end{tabular}


Table 3. Three assignments in the experiment

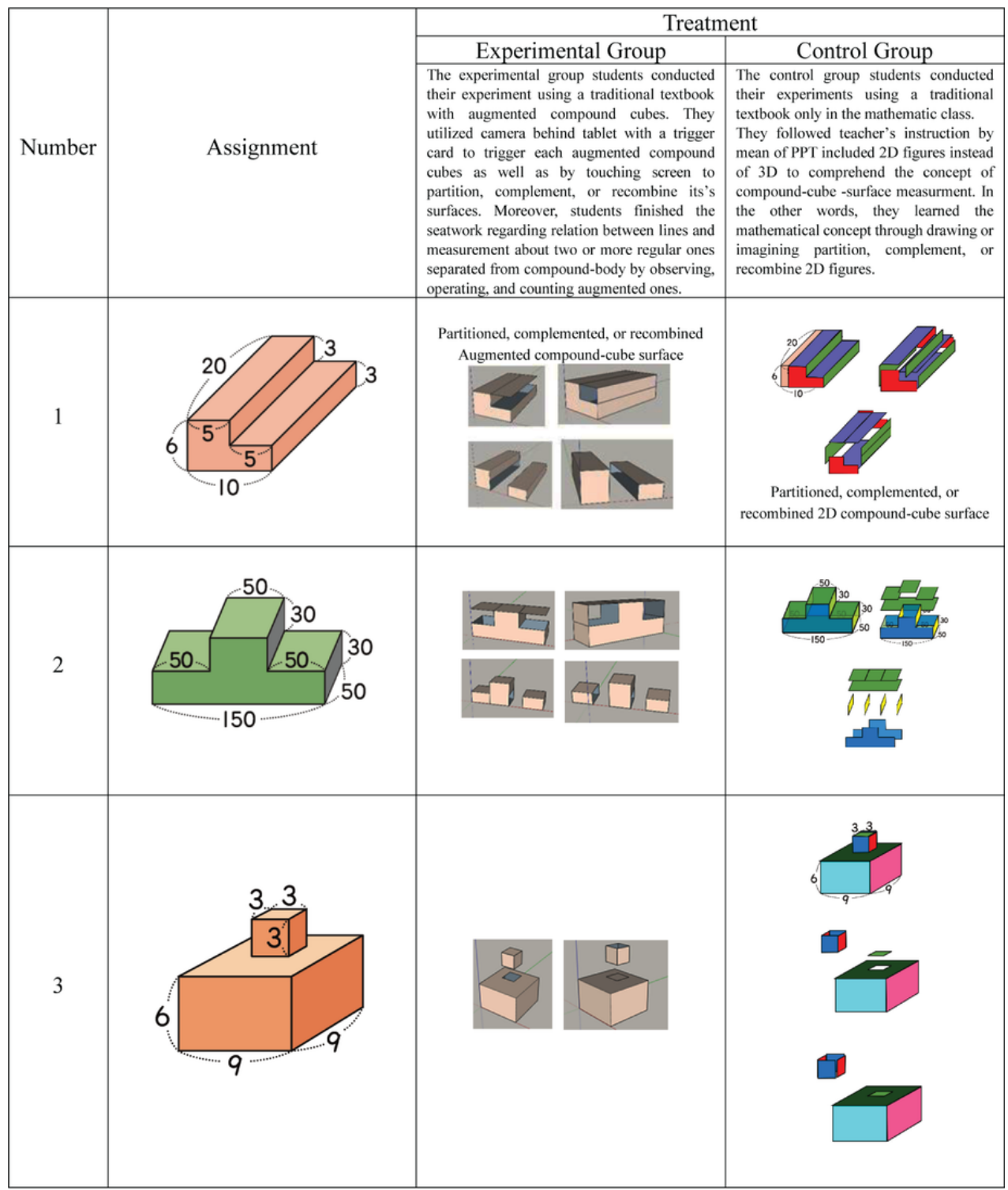

using a traditional textbook with augmented compound-cube-volume materials. The only difference in the technology assistance used by the experimental group was the augmented compound-cubevolume materials. Throughout the six-week period, no difference learning content, learning hours, and instructor apart from the experimental group.

In the first week, the instructor provided a learning packet about Aurasma App and their usage to the experimental group students. The learning packets (see Figure 1) including Instructions for Aurasma, operation sheets, seatwork sheets, and compound-cube-surface area triggers for each student. Then, the instructor guide experimental group students follow the operation sheets to operate the Aurasma running on tablet step by step. During the five-week period, the students were asked to finish the sub-tasks of sequence assignment regarding compound-cube-surface areas measurement 
Figure 1. A learning packet

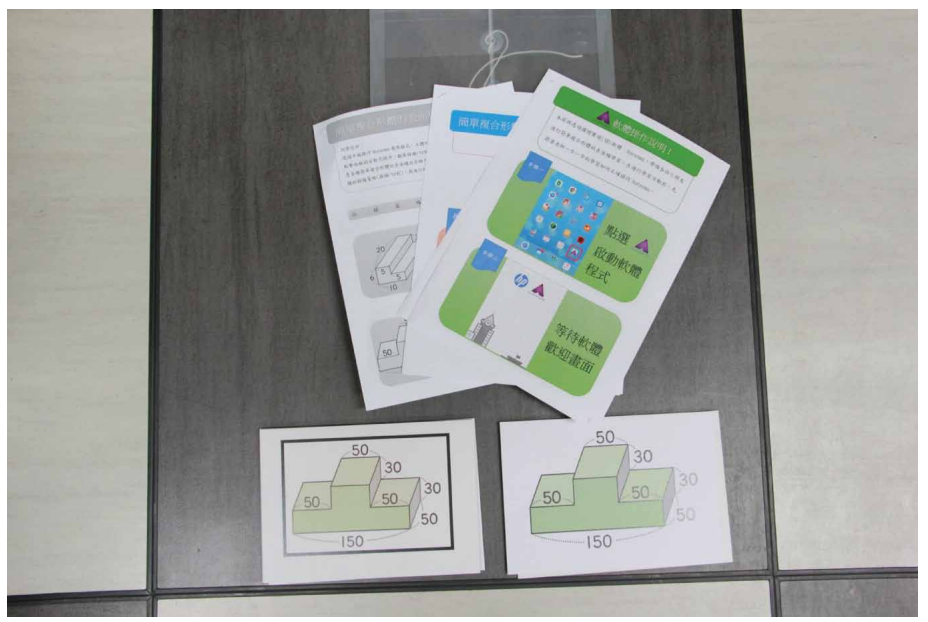

by Aurasma (see Figure 2). The content of the augmentations including pushing with complement faces as well as cutting mode step by step of compound-cube-surface areas for each assignment. Students finished the assignments through operation, observation, recording, problem solving, and group discussion via seatwork sheet and augmentations. Aspect of operation, students used the Aurasma mobile app running on iPads ( $1^{\text {th }}$ generation) to interact with augmentations by pushing some surface with complement or cutting compound cube during they are carrying out the assignments. Aspect of observation, they explored the compound cube and comprehend relationships between origination and transformation (pushing some surface with complement or cutting compound cube) of compound-cube surface by observation. Aspect of recording, they recording these relationships on seatwork sheets step by step according to observation. Aspect of problem solving, they were trying to count the compound-cube-surface areas in terms of previous recording. Aspect of group discussion, finally, some student depicted the processes of his each counting step in public for other students in class and others respond to him to assist him to reflect on those processes no matter what he is in right road or wrong. The experimental group students connected to the Internet over the wireless network used by the school. Particularly, the students used the augmented compound cube volume

Figure 2. Operating the Aurasma

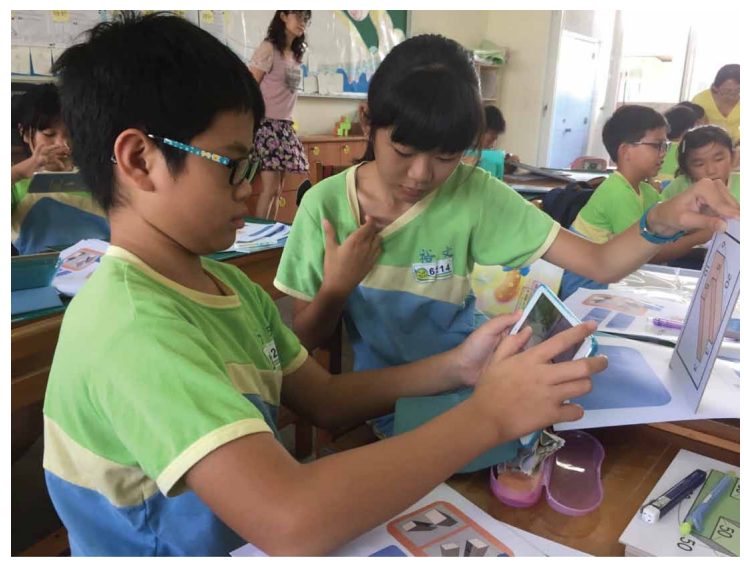


materials (see Figure 3) to comprehend the elements of compound cube volume, whereas the speed of their solving the assignments was decided by their degree of individual comprehension in this experimental environment.

\section{RESEARCH TOOL: MAR AND ITS' IMPLEMENTATION}

The MAR remedial teaching program includes operation sheets, seatwork sheets and interactively virtual objects which are inserted in triggers and operated by triggering (see Figure 4 ). The researchers design this program based on work in the literature above. The MAR remedial teaching program provided virtual 3D geometric objects as a form of concreate representation and students could

Figure 3. Using the augmented compound cube

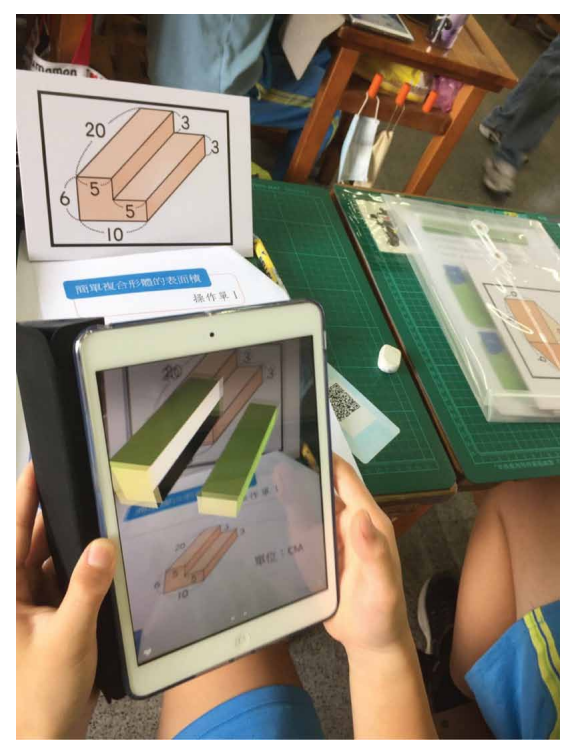

Figure 4. Virtual objects

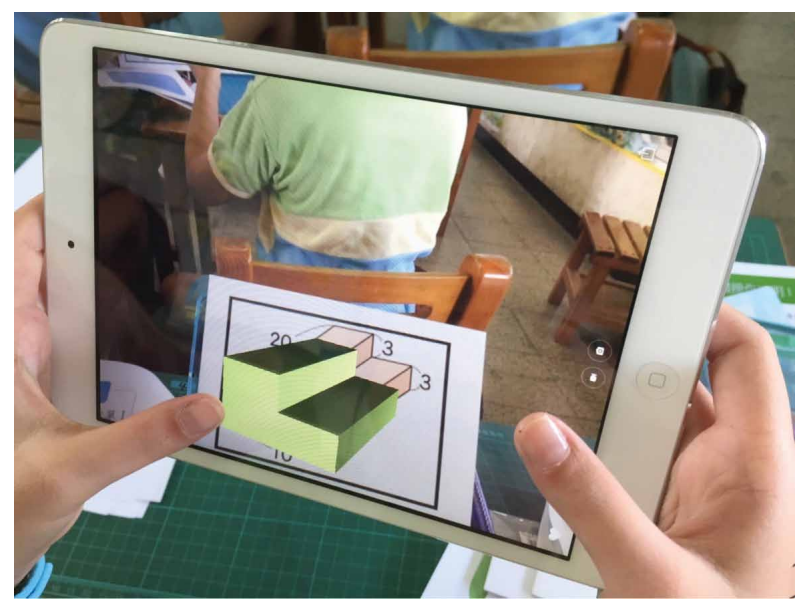


solve compound- cube-surface area problems by manipulating them. The operations of partition, complementation, and recombination are explained as following:

1. Partition: The partition operation involved break of large compound cube into different small pieces so as to simplify problem. Figure 5 show the student how to use the partition operation to break the compound cube into small pieces in needed;

2. Complementation: Sometimes it was necessary to separate some surfaces to fully complement the other cube (see Figure 6). It is useful to simplify the process of solving problems regarding compound-cube-surface area measurement and to avoid happening of counting missing and repeatedly counting;

3. Recombination: The recombination mechanism was made it possible to separate some surfaces at time into configurations with other surfaces. In Figure 7, we can see the recombination operation pushed the goal surface forward and combine with another surface to form the new one.

To model the 3D geometric cubes and its operations in the MAR remedial teaching program, the Google SketchUp 3D modeling computer program was employed, which provided creation of 3D models of buildings, furniture, interiors, landscapes, and more. It comes in multiple editions include make, pro, and free are explained as following:

Figure 5. Partition

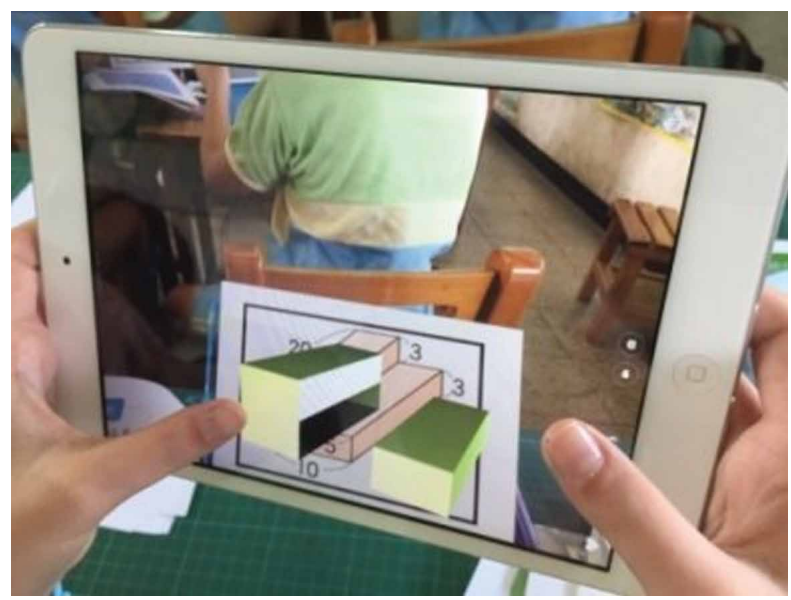

Figure 6. Complementation

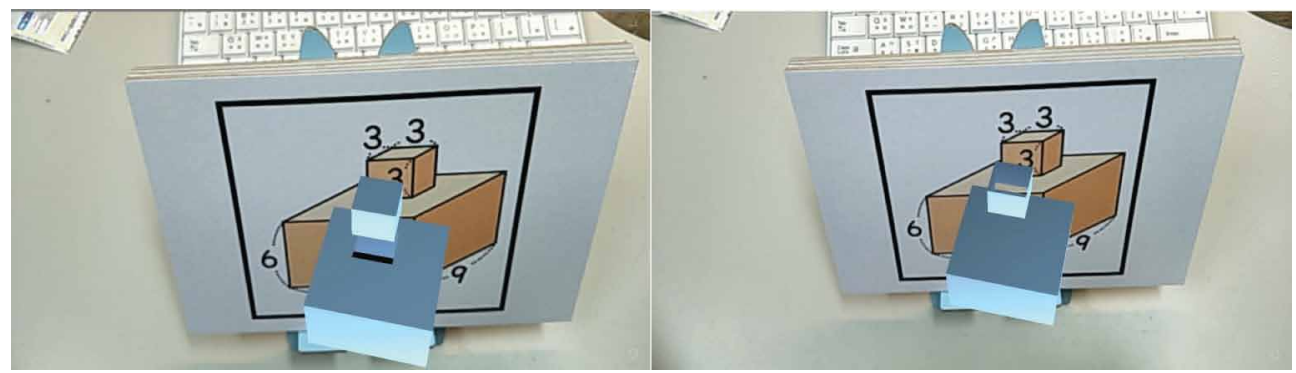




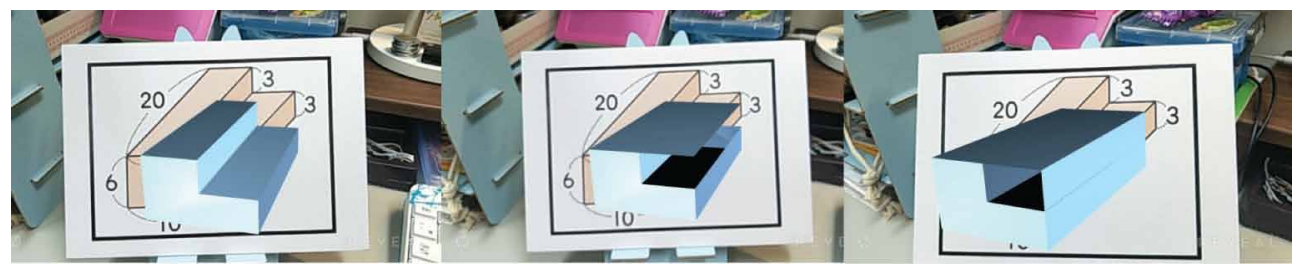

1. Make (formerly SketchUp for Home and Personal Use), introduced in May 2013, is a free-ofcharge version for home, personal and educational use;

2. Pro includes the functionality of SketchUp Make plus importers and exporters to common 2D and 3D formats, access to Layout (2D documentation software) and Style Builder (create custom edge styles for SketchUp models);

3. Free was released as a web-based application which replaces SketchUp Make.

In this study, we utilized the make version to describe the virtual 3D cubes as well as its operation in the MAR remedial teaching program.

The MAR remedial teaching program provided students easy access to operate the virtual 3D cubes by these procedures including partition, complementation, and recombination and to observe the cubes as well as the relation between its sides and surfaces when the operations were occurring.

To build scaffolding for the MAR remedial teaching program, operation sheets were employed. In the beginning, the teachers pose the first geometry problem of compound-cubesurface area measurement with the MAR remedial teaching program, in which 3D virtual cubes and its' operational model were built (see Figure 8), with the sequentially operated description given in the work sheets. All students follow the teachers' instruction to manipulate 3D virtual cubes in class step by step, utilize Ipad (Version 1) devices with AURASMA app as well as interact with the trigger card (see Figure 8) to observe the relation between its sides and surfaces when the operations were occurring. Second, all students sequentially recorded the observation values on the work sheets by themselves. Third, all students try to solve it and write the processes on the work sheets. Finally, the researchers purposively sampled the students to explain their solving processes in public and guided all students to carry out discussion in regarding to those processes. Students could immediately revise their solutions according to the comments given by others. After class, they were assigned seatwork sheets without the MAR remedial teaching program to confirm the effect of theirs' learning retention.

\section{RESULTS AND DISCUSSION}

\section{Achievement}

Due to our experiment design includes two types of independent variables are independent samples and paired-sample respectively, two-way ANOVA with mixed design was conducted on students' pretest scores and posttest scores by researchers. Independent samples include two variables are experimental group (Exp.) and control group (Con.). Whereas paired-sample includes two variables are pretest and posttest. The researchers obtained some results from different groups with respect to pretest and posttest respectively as follows and summarized further in Table 4:

1. There was a reciprocal effect $(\mathrm{F}=4.451, \mathrm{P}=.039<.05)$ on test and group and that effect relation could be seen clearly in Figure 10; 
Figure 8. 3D virtual cubes and its' operational model

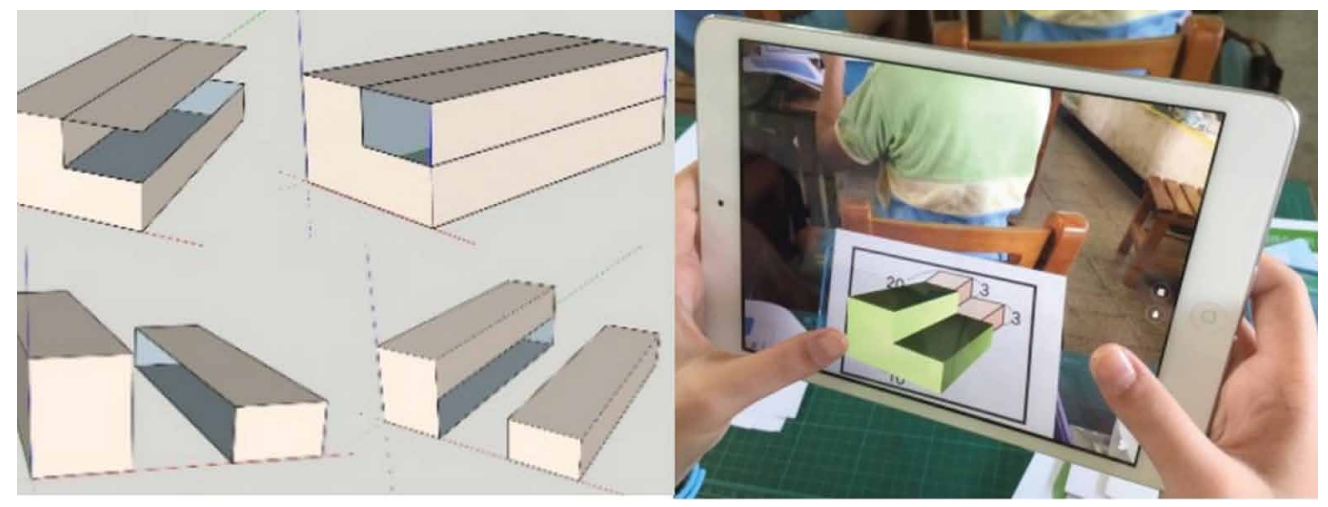

Table 4. Analysis of paired-sample respectively, two-way ANOVA

\begin{tabular}{|c|c|c|c|c|}
\hline Source & SS & df & MS & $\mathbf{F}$ \\
\hline Group & 83.333 & 1 & 83.333 & .101 \\
\hline test & 6900.833 & 1 & 6900.833 & $30.086^{* * *}$ \\
\hline test * Group & 1020.833 & 1 & 1020.833 & $4.451^{* * *}$ \\
\hline Error(Group) & 47771.667 & 58 & 823.649 & \\
\hline Error(test) & 13303.333 & 58 & 229.368 & \\
\hline \multicolumn{5}{|l|}{ Group } \\
\hline Pretest & 843.750 & 1 & 843.750 & 1.933 \\
\hline Postest & 260.417 & 1 & 260.417 & .422 \\
\hline \multicolumn{5}{|l|}{ Test } \\
\hline Exp. & 6615.000 & 1 & 6615.000 & $37.177 * * *$ \\
\hline Con. & 1306.667 & 1 & 1306.667 & $4.653 * *$ \\
\hline
\end{tabular}

${ }^{* *} P<.05{ }^{* * *} P<.001$

2. There was no significant difference $(\mathrm{F}=1.933, \mathrm{P}=0.170>.05)$ on pretest between experimental group and control group;

3. There was no significant difference $(\mathrm{F}=.422, \mathrm{P}=0.518>.05)$ on posttest between experimental group and control group;

4. There was significant difference $(\mathrm{F}=37.177, \mathrm{P}=.000<.01)$ in experimental group between pretest and posttest;

5. There was significant difference $(\mathrm{F}=4.653, \mathrm{P}=.039<.05)$ in control group between pretest and posttest.

\section{Content Analysis}

The researchers posed nine geometry problems regarding compound-cube-surface measurement in this study. All problem-solving operations divided into three categories, partition, complementation and recombination. Since these cubes were not regular, it couldn't be straightforward to figure out the math rules need to get the answers. Hence, students need to separate, complement, or recombine cubes into regular shape to find an efficient way to get answer via MAR remedial teaching program. 


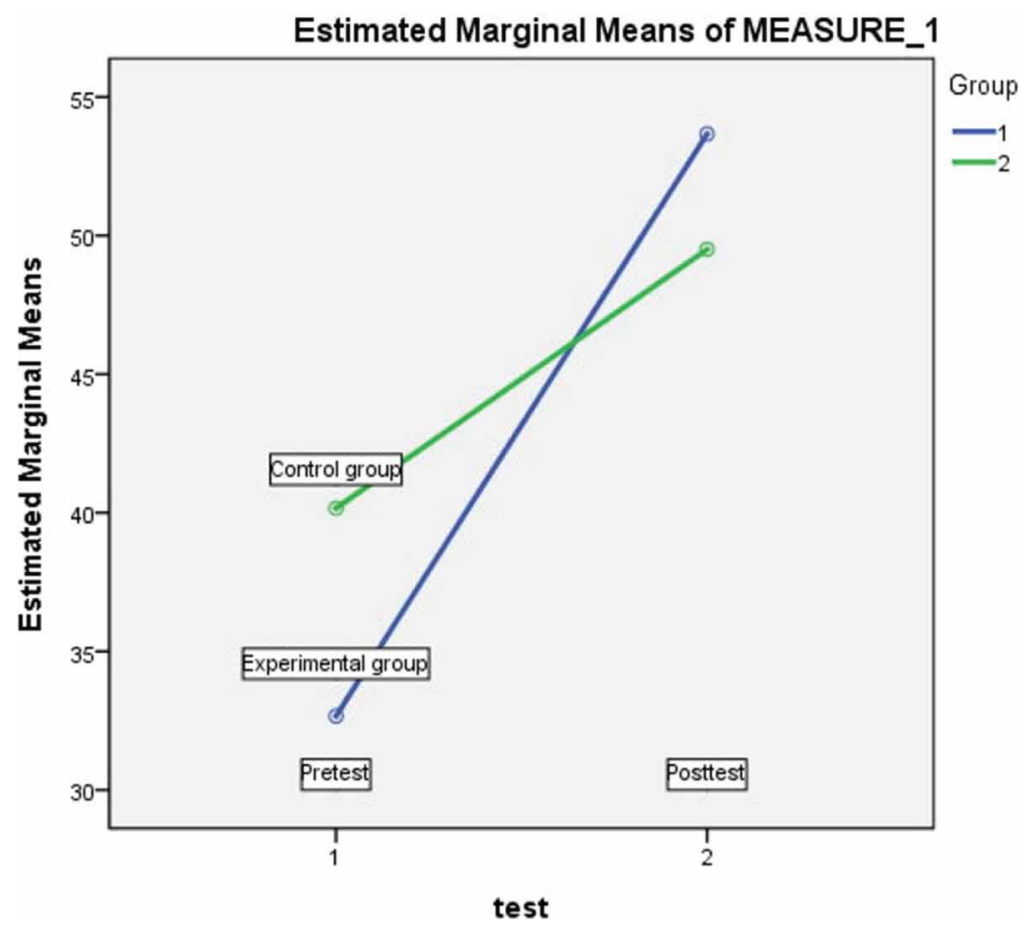

The students' problem-solving sheets were analyzed to find the error types generated form the process of solving questions due to their uncomplete spatial abilities. To show error types clearly, the description of and the statistical distribution of it were given as follows and summarized further in Table 5:

1. The researchers summarized five error types, such as "confused with the volume and the surface area", "loss", "repeated calculation", "the solutions through expanded view isn't completed", and "others";

2. The others included calculation error, incomplete, correspond to the error side and blank;

3. Compare with pretest and posttest, the Table 5 reveals the decreased tread of error types;

4. According to the trend of students' decreased error rate at aspect of "confused with the volume and the surface area", the researchers found the majority of students gained the assistance in distinguishing the concepts of volume and the surface area except V1 and V7;

5. According to the trend of students' decreased error rate at aspect of "loss", the researchers found the majority of students gained the assistance in avoiding loss during problem solving except V6 and V8;

6. According to the trend of students' decreased error rate at aspect of "repeated calculation", the researchers found the majority of students gained the assistance in exact calculation regarding surface area except V2 and V7;

7. According to the trend of students' decreased error rate at aspect of "the solutions through expanded view isn't completed", the researchers found the majority of students gained the assistance in developing themselves' spatial abilities instead of remembering the formula through expanded view except V5 and V8;

8. According to Table 5, the researchers found the trend of students' decreased error rate at aspect of "others". 
Table 5. The statistical distribution of error types

\begin{tabular}{|l|l|l|l|l|l|l|l|l|l|l|}
\hline & \multicolumn{2}{|c|}{$\begin{array}{c}\text { Confused With } \\
\text { the Volume and } \\
\text { the Surface Area }\end{array}$} & \multicolumn{2}{|c|}{ Loss } & \multicolumn{2}{|c|}{$\begin{array}{c}\text { Repeated } \\
\text { Calculation }\end{array}$} & $\begin{array}{c}\text { The Solutions } \\
\text { Through } \\
\text { Expanded View } \\
\text { Isn't Completed }\end{array}$ & \multicolumn{3}{c|}{ Others } \\
\hline & Pretest & Postest & Pretest & Postest & Pretest & Postest & Pretest & Postest & Pretest & Postest \\
\hline V1 & $7.5 \%$ & $12 \% *$ & $11.5 \%$ & $0 \%$ & $0 \%$ & $0 \%$ & $0 \%$ & $0 \%$ & $0 \%$ & $0 \%$ \\
\hline V2 & $15.9 \%$ & $0 \%$ & $3.8 \%$ & $3.8 \%$ & $0 \%$ & $3.85 \% *$ & $3.8 \%$ & $0 \%$ & $11.5 \%$ & $7.3 \%$ \\
\hline V3 & $13 \%$ & $0 \%$ & $13 \%$ & $3.85 \%$ & $30 \%$ & $3.85 \%$ & $16 \%$ & $0 \%$ & $5 \%$ & $7.3 \% *$ \\
\hline V4 & $13 \%$ & $0 \%$ & $33 \%$ & $19 \%$ & $18 \%$ & $0 \%$ & $10 \%$ & $0 \%$ & $18 \%$ & $4 \%$ \\
\hline V5 & $12 \%$ & $4 \%$ & $12 \%$ & $0 \%$ & $26.5 \%$ & $0 \%$ & $0 \%$ & $4 \% *$ & $11.5 \%$ & $7 \%$ \\
\hline V6 & $27 \%$ & $0 \%$ & $23 \%$ & $42 \% *$ & $23 \%$ & $0 \%$ & $0 \%$ & $0 \%$ & $12 \%$ & $35 \% *$ \\
\hline V7 & $12 \%$ & $31 \% *$ & $31 \%$ & $4 \%$ & $4 \%$ & $8 \% *$ & $0 \%$ & $0 \%$ & $38 \%$ & $26 \%$ \\
\hline V8 & $36 \%$ & $31 \%$ & $12 \%$ & $19 \% *$ & $8 \%$ & $0 \%$ & $0 \%$ & $4 \% *$ & $29 \%$ & $15 \%$ \\
\hline V9 & $38 \%$ & $35 \%$ & $15 \%$ & $15 \%$ & $0 \%$ & $0 \%$ & $0 \%$ & $0 \%$ & $24 \%$ & $12 \%$ \\
\hline
\end{tabular}

* Pretest<Posttest

\section{CONCLUSION}

In this paper, the MAR remedial teaching program was proposed to promote a visualized and operable system to assist students in solving geometry problems regarding compound-cube-surface area as well as foster theirs' spatial abilities. The proposed system was evaluated with using an examination and the results showed two groups' posttest scores both are better than pretest ones, but progress of experimental one between pretest and posttest is obviously better than control one. In the other words, the experimental one which utilized the MAR remedial teaching program gained the big assistance than control one. As the same as Wu, Jia, Yueh, \& Jian (2009) stated, students can study the problem by manipulating virtual 3D objects and they can find out the solutions via observation of the manipulated 3D theme. Angel (1996) also stressed that visualization is a basic component in learning and teaching 3D geometry and computers can play a very relevant part in helping students to acquire and develop abilities of visualization in the context of space geometry. Whereas the MAR remedial teaching program involved manipulated virtual 3D objects and visualization, the researchers infer the MAR remedial teaching program is benefit students on solving geometry problems regarding compound-cube-surface area. Considering the user-interface (UI) will be a major improvement in the next generation if the program.

The students' problem-solving sheets were analyzed to find the error types generated form the process of solving questions, and to aware and analyze experimental effect. The result revealed manifestly decreased quantity of error types and decreased rate of error on basic questions (V1, V2, V3, V4, V5) regarding convex cubes. Nevertheless, the similar effect couldn't be found on advanced questions (V6, V7, V8, V9) regarding concave cube. According to researchers' further analysis found, the tread of students' error rate at aspect of "confused with the volume and the surface area" and "loss" occupied most of error rates on advanced questions (V6, V7, V8, V9). The phenomena revealed that students were affected by visual-obscuration to inexactly carry out their count as well as were controlled over the shapes of cubes (concave) to execute wrong arithmetic (minus).

As a result of our study, the researchers conclude that the MAR remedial teaching program truly played a scaffolding role on solving compound-cube-surface areas. It provided virtual objects, nearly real ones, to students to construct an friendly environment involves mental image and visualization. Yet, the researchers also found there are still some questions needed to probe in the future, such as 
students were affected by visual- obscuration to inexactly carry out their counts. Even so, the MAR remedial teaching program indeed benefits students in solving compound-cube-surface areas better than traditional one, which could be certified from pretests and posttests.

The present findings contribute to the field's understanding of utilizing AR-technology for learning mathematic compound-cube-surface area at elementary school. Besides it, they could be applied to improve students' spatial abilities to further enhance their learning performance on subject of mathematic compound-cube-surface area. In general, they will be valuable to better the learning methodology in comprehending the compound-cube-surface area and particular provide students easily access to the subject. 


\section{REFERENCES}

Angel, G. (1996). Visualization in 3-dimensional geometry. In search of a greamework. Proceeding $20^{\text {th }}$ international conference of the P. M. E., 1, 3-19.

Arvanitis, T. N., Petrou, A., Knight, J. F., Savas, S., Sotiriou, S., Gargalakos, M., \& Gialouri, E. (2007). Human factors and qualitative pedagogical evaluation of a mobile augmented reality system for science education used by learners with physical disabilities. Personal and Ubiquitous Computing, 13(3), 243-250. doi:10.1007/ s00779-007-0187-7

Battista, M. (2003). Understanding students' thinking about area and volume measurement. In D. H. Clements \& G. Bright (Eds.), Learning and teaching measurement (pp. 122-142). Reston, VA: National Council of Teachers of Mathematics.

Berthelot, R., \& Salin, M. H. (1998). The role of pupils' spatial knowledge in the elementary teaching of geometry. In C. Mammana \& V. Villani (Eds.), Perspectives on the teaching of geometry for the $21^{\mathrm{st}}$ Century (pp. 71-78). Dordrecht: Kluwer.

Bishop, A. (1980). Spatial abilities and mathematics education: A review. Educational Studies in Mathematics, 11(3), 257-269. doi:10.1007/BF00697739

Bishop, A. J. (1983). Spatial abilities and mathematical thinking. In Proceedings of the IV I.C.M.E (pp. 176178). Birkhäuser.

Brown, D. L., \& Wheatley, G. H. (1997). Components of imagery and mathematical understanding. Focus on Learning Problems in Mathematics, 19(1), 45-70.

Campbell, D. T., \& Stanley, J. C. (1996). Experimental and quasi-experimental designs for research. Boston: Houghton Mifflin Co.

Chen, Y. S., Kao, T. C., \& Sheu, J. P. (2003). A mobile learning system for scaffolding bird watching learning. Journal of Computer Assisted Learning, 19(3), 347-359. doi:10.1046/j.0266-4909.2003.00036.x

Danakorn, N., Mohamad, B. A., Noor, D. A. H., \& Mohd, H. A. R. (2013). Mobile Augmented Reality: The potential for education. Social and Behavioral Sciences, 103, 657-664. doi:10.1016/j.sbspro.2013.10.385

Denk, M., Weber, M., \& Belfin, R. (2007). Mobile learning-challenges and potentials. International Journal of Mobile Learning and Organization, 1(2), 122-139. doi:10.1504/IJMLO.2007.012674

Duval, R. (1998). Geometry from a cognitive point of view. In C. Mammana \& V. Villani (Eds.), Perspectives on the teaching of geometry for the 21st century: An ICMI study. Dordrecht: Kluwer.

FitzGerald, E., Adams, A., Ferguson, R., Gaved, M., Mor, Y., \& Thomas, R. (2012). Augmented reality and mobile learning: the state of the art. In 11th World Conference on Mobile and Contextual Learning (mLearn 2012), Helsinki, Finland.

Gervautz, M., \& Schmalstieg, D. (2012). Anywhere Interfaces Using Handheld Augmented Reality. Computer, 47(7), 26-31. doi:10.1109/MC.2012.72

Gulcin, T. S., \& Meral, A. (2015). A Study on Sixth Grade Students' Misconceptions and Errors in Spatial Measurement: Length, Area, and Volume. International Journal of Science and Mathematics Education, 14(7), 1293-1319. doi:10.1007/s10763-015-9642-5

Gutiérrez, A. (1996). Visualization in 3-dimensional geometry: In search of a framework. Proceedings of the 20th International Conference of the P.M.E., 1, 3-19.

Hiebert, J. (Ed.). (1986). Conceptual and procedural Knowledge: The case of mathematics. Hillsdale, NJ: Erlbaum.

Hwang, G. J., Yang, T. C., Tsai, C. C., \& Yang, S. J. H. (2009). A context-aware ubiquitous learning environment for conducting complex science experiments. Computers \& Education, 53(2), 402-413. doi:10.1016/j. compedu.2009.02.016

Kilpatrick, J., Swafford, J., \& Findell, B. (2001). Adding it up: Helping children learn mathematics. Washington, DC: National Academy of Sciences-National Research Council. Retrieved on November 16, 2018 from http:// www.nap.edu/catalog/9822.html 
Kosslyn, S.M. (1980). Image and mind. Harvard U.P.

Martín, S., Díaz, G., Cáceres, M., Gago, D., \& Gibert, M. (2012). A Mobile Augmented Reality Gymkhana For Improving Technological Skills And History Learning: Outcomes And Some Determining Factors. In T. Bastiaens \& G. Marks (Eds.), Proceedings of World Conference on E-Learning in Corporate, Government, Healthcare, and Higher Education 2012 (pp. 260-265). Academic Press.

McGee, M. G. (1979). Human spatial abilities: Psychometric studies and environmental, genetic, hormonal, and neurological influences. Psychological Bulletin, 86(5), 889-918. doi:10.1037/0033-2909.86.5.889 PMID:386403

Parzysz, B. (1988). Problems of the plane representation of space geometry figures. Educational Studies in Mathematics, 19(1), 79-92. doi:10.1007/BF00428386

Santoso, M., Yan, W. F., \& Gook, L. B. (2012). Development of Edutainment Content for Elementary School Using Mobile Augmented Reality. 4th International Conference on Computer Research and Development IPCSIT, 39.

Schmalstieg, D., \& Wagner, D. (2007). Experiences with Handheld Augmented Reality. 6th IEEE and ACM International Symposium on Mixed and Augmented Reality, 1-13.

Sergey, S., Fedor, Z., \& Pavel, C. (2015). Interactive Educational Content Based on Augmented Reality and 3D Visualization. Procedia Computer Science, 66, 720-729. doi:10.1016/j.procs.2015.11.082

Smith, J. P. (2007). Tracing the origins of weak learning of spatial measurement. Presentation at the Mathematics Education Colloquium, Michigan State University, East Lansing, MI. Retrieved on November 16, 2018 from https://www.msu.edu/ stemproj/presentations/STEM_MSUColloquium_2007.pdf

Sommerauer, P., \& Müller, O. (2014). Augmented reality in informal learning environments: A field experiment in a mathematics exhibition. Computers \& Education, 79, 59-68. doi:10.1016/j.compedu.2014.07.013

Squire, K., \& Klopfer, E. (2007). Augmented Reality Simulations on Handheld Computers. Journal of the Learning Sciences, 16(3), 371-413. doi:10.1080/10508400701413435

Tarng, W., \& Ou, K.-L. (2012). A Study of Campus Butterfly Ecology Learning System Based on Augmented Reality and Mobile Learning. 2012 IEEE Seventh International Conference on Wireless, Mobile and Ubiquitous Technology in Education, 62-66.

Thompson, A. G., Philipp, R. A., Thompson, P. W., \& Boyd, B. A. (1994). Calculational and conceptual orientations in teaching mathematics. In A. Coxford (Ed.), 1994 Yearbook of the NCTM (pp. 79-92). Reston, VA: NCTM.

Uzunboylu, H., Cavus, N., \& Ercag, E. (2009). Using mobile learning to increase environmental awareness. Computers \& Education, 52(2), 381-389. doi:10.1016/j.compedu.2008.09.008

Waller, L. A. (2005). Spatial models for categorical data. In Encyclopedia of biostatistics. Wiley.

Wu, Y. H., Jia, H. S., Yueh, M. H., \& Jian, J. D. (2009). A Study of multi-representation of geometry problem solving with virtual manipulatives and whiteboard system. Education Technology \& Society, 12(3), 229-247.

Zurita, G., \& Nussbaum, M. (2004). A constructivist mobile learning environment supported by a wireless handheld network. Journal of Computer Assisted Learning, 20(4), 235-243. 


\section{APPENDIX}

Table 6.

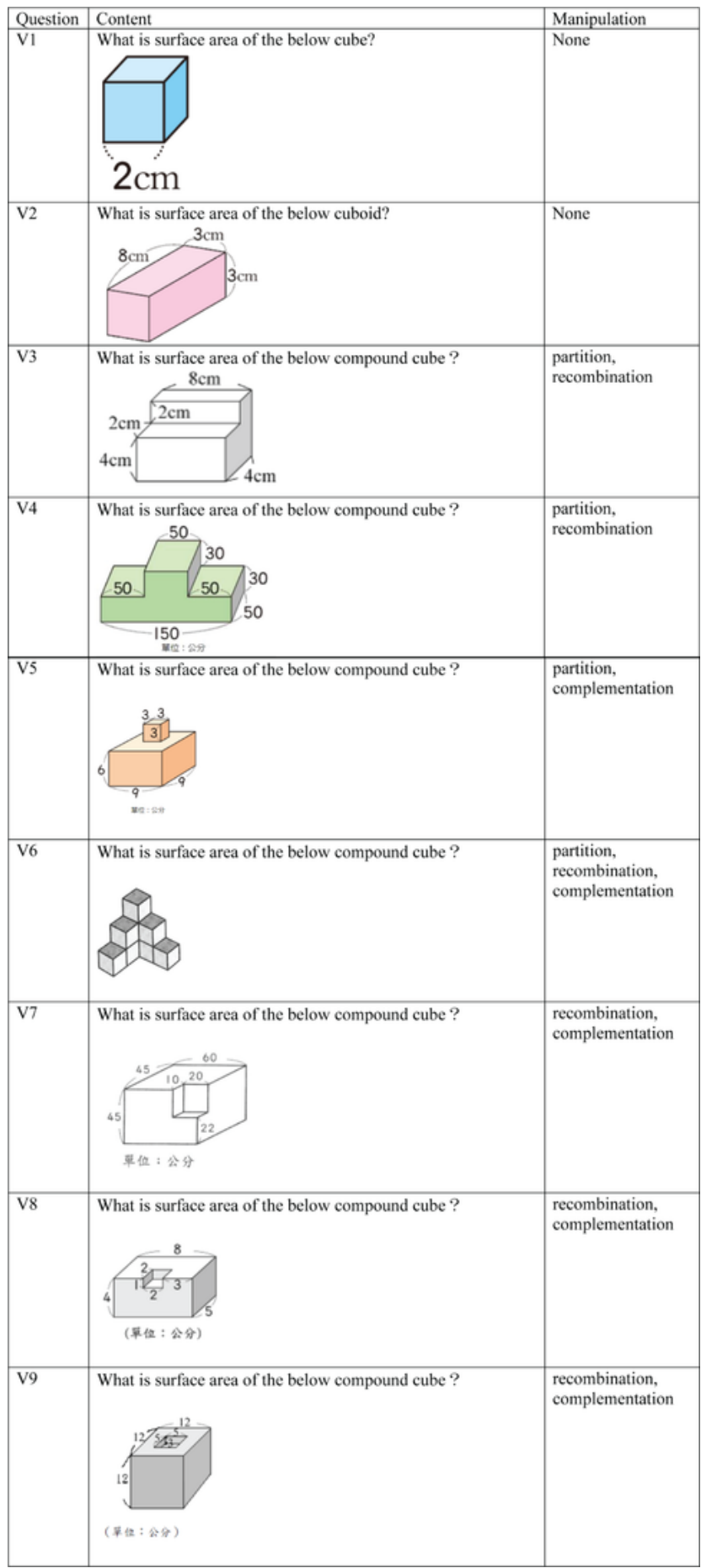


Koun Tem Sun is currently a professor of the Department of Information and Learning Technology at National University of Tainan and had served as a Dean of Academic. Expertise in artificial intelligence, digital learning, and cognitive science.

Meng Hsun Chen is Ph D. student at National University of Tainan. Expertise in E-learning, cognitive science. 